\title{
Representation of New Media in Cinematographic Apparatuses: Critical Analysis of “The Social Network" as One of the Social Media Themed Hollywood Movies
}

\section{Tutku Akter, Eastern Mediterranean University, TRNC}

\begin{abstract}
As new and old media articulate with each other, it is possible to find traces of each media in the other one. Although new media is fed from old media by re-telecasting [rebroadcasting] what has been telecasted [broadcasted] in old media, old media subject new media in to its various programs or products. As it is known, cinema, which can be considered as old media and as an ideological state apparatus, is one of the influential medium in the process of naturalizing and normalizing 'dominant' as dominant. Because of this, representation of new media in old media is explored to understand how the dominant power relations or old mainstream media represent or portray new mainstream or new (?) dominant power relations. During the present study, "unchanging political economic structures in the field of media industry" and the way they legitimate and naturalize their superiority is the main argument that has been taken for granted. For the purpose of the present study, the motion-picture "The Social Network" is analyzed in terms of investigating how the messages were coded and how the reality of Facebook as a new product of dominant power relations was constructed.
\end{abstract}

Key words: Cinema, power relations, new media, SNS, representation. 


\section{Introduction}

New media as one of the innovations, which made a breakthrough especially within the context of social communication, necessitated redefining the 'new' about media. Lexical meaning of new, as it is known, is "produced, introduced, or discovered recently or now for the first time; not existing before", "not previously used or owned", "different from a recent previous one" or "in addition to another or others already existing" (Online Oxford Dictionary). However, is new media really "new" in the sense of being first time? It did not exist before as it is but its essence is a combination of other means of communication. To be new, it needs to be recently discovered, introduced or produced. Is it really different from a recent previous one or is it an innovated, improved version of them? But surely, it is in addition to other already existing [traditional mass media].

As new and old media articulate with each other, it is possible to find traces of each media in the other one. Although new media feeds from old media via re-telecasting [rebroadcasting] what has been telecasted [broadcasted] in old media, old media subjects new media in to its various programs or products. It is possible to state that the means of communication are articulated, not only between each other but also within themselves. The present study focuses on representation of new media in old media to determine how the dominant power relations or old mainstream media represent or portray new mainstream or new (?) dominant power relations. During the present study, "unchanging political economic structures in the field of media industry" and the way they legitimate and naturalize their superiority is the main argument that was taken for granted. How new media, which is dominated by dominant power relations and is a product of the dominant power relations, is represented in mainstream media is analyzed in the study. Within this context, the aim is to determine the method of naturalizing and legitimating an 'innovation' [novelty], which can be assumed to be its own product.

The purpose of the study is to examine how 'Facebook' as one of the most leading Social Network Site (SNS) was represented in Hollywood cinema, how the messages were coded, and how the reality of SNS as a new product of dominant power relations was constructed in the drama and biography films. 


\section{Context}

"Cinema is the ultimate pervert art. It doesn't give you what you desire - it tells you how to desire.”(Slavoj Žižek)

Culture industry, which was suggested by Adorno and Horkheimer (1977/1944), is one of the consequences of the cultural influences of mass media. They were suggesting that "culture is dominated by commodities produced by culture industry and that these commodities, while purporting to be democratic, individualistic and diversified, are in actuality authoritarian, conformist and highly standardized" (Barker, 2004). The basic feature of the culture industry is standardizing by vulgar media entertainment. The reason for its success, unlike real world, is because audiences do not make any effort when consuming its products. According to Adorno, culture industry produced by popular media detracts audiences from political agency and social progressivism (Laughey, 2010); thus, as Barker (2004) suggests, it engenders ego weaknesses and the authoritarian personality. Of course, it is not possible to eliminate the uses and gratification provided by media and relates culture industry only to the capitalist standardization. Hollywood cinema, which serves the ideological benefits and interests of the dominant class, can be counted as product of culture industry. Baudry, who was one of the scholars who drew attention to the ideological structure of Hollywood cinema, states that to bring about social and political change, cinematic forms opposed to Hollywood style cinema need to be developed and created to bypass dominant ideology (Rushton and Bettinson, 2010).

Baudry, as one of the most recognized Hollywood critic, takes the Althusserian perspective to construct interrelation between ideology and cinema. For this reason, he adopts ideological state apparatus to the cinema and film industry as an outcome of culture industry. He suggests four sensitive issues; the first highlights the functioning of ideological state apparatuses and their role in reinforcing execution of repressive state apparatuses. Within this context he rationalized his idea about the ideological structure of the cinematographic apparatuses, by defining their purpose as serving the benefits and interests of upholding power. The second issue is about the similarity between ideology and the purpose of the cinema at representing the imaginary relationship of individuals to their real conditions of existence. According to him, as third issue, cinematic apparatus has methods of representing and is able to represent anything in an imaginary manner. 
The term cinematographic here, for Baudry, "refers to a work, that is, to process of transformation" (Nichols, 1976, p. 533). Cinematographic apparatuses, as Baudry claims, interpellate individuals [spectators] as subjects same as ideologies do. By subjecting individuals, it controls the perception of spectators regarding themselves also. Finally, as the fourth issue, he draws attention to the possibility of creating real relations by disconnecting from the ideology of the dominant class, so bypassing dominant ideology via cinematic forms opposed to Hollywood cinema. He, at this point, handles ideology as a science and claims that scientific knowledge of real relationship of production can then be analyzed (Rushton and Bettinson, 2010). Then, how does cinema function as an ideological state apparatuses? Although the possibility of listing innumerable criteria is tough, I just want to draw attention to the representation and the language at this point.

As mentioned above, ideology is a representation; nevertheless, it needs to be said that in parallel with this fact, representation itself is ideological. Representation is affined with media, which gives meaning to the produced, because of it being a process of identification. It influences our perception about the world and about ourselves through a particular perspective and for certain purposes because of being ideological. As Williams (1985) defined, ideology is an "abstract and false thought, in a sense directly related to the original conservative use but with the alternative -knowledge of real material conditions and relationships - differently stated" (p.155). The system of this knowledge can be traced to cinematic apparatus, Baudry assumes, which has gravitated toward rejecting difference in favor of unity via its three peculiarities: screen-mirror [inspired from Lacanian perspective; mirror stage]; movement, continuity and unity; and perspective (Rushton and Bettinson, 2010).

On the other hand, as Rushton and Bettinson (2010) claimed, Metz draws attention to another important characteristic of cinema, which enables us to call it ideological, cinematic signifier. Unlike Baudry, Metz deals with the language and its ability to create meaning. Metz more likely was inspired from the Freudian perspective and adapted two concepts to cinema to define imaginary signifiers; Fetishism and mirror-stage [as one "which the absent image is (mis)taken for presence" (Rushton and Bettinson, 2010, p. 44)]. For him, every film or 
cinema is imaginary because of the mode of presentation. They not only present us imaginary stories and scenes but the way of presenting them is also imaginary.

Screen Theory, which "poses the problem of the 'politics of the signifier'....exclusively at the level of the 'subject'....." (Morley 2005, p.154), is a Marxist film theory associated with the British journal Screen in the 1970s. MacCabe, one of the most known theoreticians of this approach, was criticizing Hollywood cinema within the context of 'realism'. He was defining one of the main purposes of cinema as 'representing' reality as the way to display the reality. However, for him this was not possible because of the structure of the reality itself. The beliefs, relations, and knowledge is the reality, not the things that we perceive, as MacCabe suggests. Therefore, reflected reality or truth is inefficient to explain the true nature of the world and articulation of the social relations in it (Rushton and Bettinson, 2010) so that cinema can only be an ideological construction, not the truth. As Sire (2010:215) stated "Truth cannot be constructed. To live in ideology is, as Havel so eloquently reminds us, inevitably to live in a lie. Truth can only be revealed. We cannot be creators, only receptors."

\section{Representation, re-presentation of coded messages}

Representation is closely related with the power of media within the context of giving meaning to what is produced. Representation is the signification and identification of coded 'reality'. Media representations give us an idea about everything, even the things that we did not experience or see, thus constructs our 'realities'. However, when representing 'them', media do not reflect it is as it is. They are just 'given' to us from some particular point of view. Reality can be experienced only by the reader. Moreover, media representations strongly influence our experiences as well as our perception and interpretation of the world. Because we born in an already constructed socio-cultural system, our perceptions that are taught to us within it, would be closely related to what is 'represented' (Laughey, 2010).

Hall (2005) talks about three hypothetical positions of coding; dominant-hegemonic position (the viewer operates inside the dominant code), negotiated code (reader mostly accepts the intended reading but partly shares it), and counter-hegemonic code (the reader directly receives the intended meaning but does not share and rejects the reading). According to him, the denotative meanings are closed unlike connotative meanings. By emphasizing activeness of transformations of connotative meanings, he was addressing polysemy not pluralism. 
However, in other respects, he highlights the constitutional role of society on encoding messages by claiming "Any society/ culture tends, with varying degrees of closure, to impose its classifications of the social and cultural and political world" (p.123). Therefore, he draws attention to the ideological structure of coding.

When distinguishing visual signs from aural ones, Hall underlines being as the 'naturalized' feature of visual codes. He assumes that codes that seem as natural, indeed, are the ones that are cultural-specific codes. They are perceived as natural because of being iconic signs and are read as natural unlike linguistic signs by reason of being less arbitrary (Hall, 2005).

Therefore, representation, portrayal or format of encoding the 'subject', plays a significant role at the perception of spectators and at how they construct the 'reality' of the thing that is being described. To understand its function of informing and manipulating its audiences about itself, it is necessary to study how media represent itself. According to some researches, the most used social media are Facebook, Twitter, Linkedin, Google, Youtube, Pinterest, Instagram, Tumblr, and Flickr (See Table 1).

\begin{tabular}{lll}
\hline Social Media & \multicolumn{1}{c}{ Owner } & \multicolumn{1}{c}{ Country of origin } \\
\hline Facebook & Mark Zuckerberg & Cambridge, Massachusetts, USA \\
\hline Twitter & Jack Dorsey & San Francisco, California, USA \\
\hline Linkedin & Reid Hoffman and his Team & Mountain View, California, USA. \\
\hline Google & Alphanet Inc. & Menlo Park, California, USA \\
\hline Youtube & Google (so Alphanet Inc.) & Menlo Park, California, USA \\
\hline Pinterest & Cold Brew Labs, Inc. & San Francisco, California, USA \\
\hline Instagram & Facebook (so Mark Zuckerberg) & Cambridge, Massachusetts, USA \\
\hline Tumblr & Yahoo! & Santa Clara, California, USA \\
\hline Flickr & Yahoo! & Santa Clara, California, USA \\
\hline
\end{tabular}

Table 1. Most used social media and Ownership

[Source: Sareah, F. (Jul 26, 2015). Interesting Statistics for the Top 10 Social Media Sites. Retrieved from: http://smallbiztrends.com/2015/07/social-media-sites-statistics.html] 
It is also noted that all of these nine most popular social media's country of origin is the United States. Facebook and Instagram are owned by Mark Zukerberg, Google and Youtube by Alphanet Inc., Tumblr and Flickr are owned by Yahoo! Twitter by Jack Dorsey, Linkedin by Hoffman and his Team, and Pinterest is owned by Cold Brew Labs, Inc. Moreover, as of August 2015, statistics of leading social networks worldwide state that the majority of SNS's country of origin is the United States too (see graphic 1).

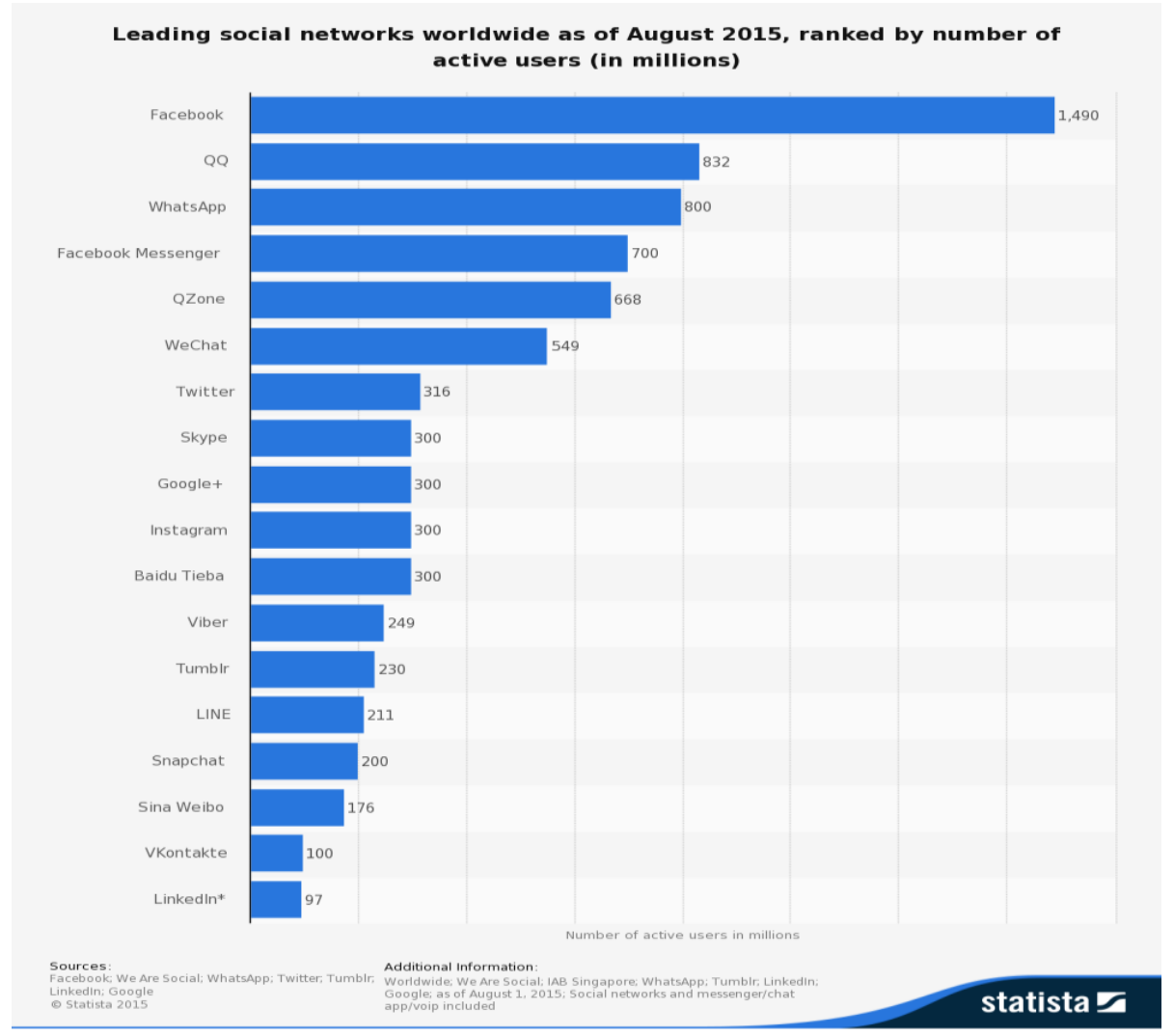

Graphic 1. The statistics of leading social networks worldwide as of August 2015 [Retrieved from: http://www.statista.com/statistics/272014/global-social-networks-ranked-bynumber-of-users/]

Under these circumstances, it is essential to clarify what is the 'new' about the new media. It is obvious that within the political economic sense, nothing has changed in new media when compared with the traditional mass media. Dominant ruling class still dominates the media as can be clearly traced from the statistical data. Out of 18 leading social networks worldwide, country of origin of 10 SNS's is the United States (55.6\%), country of origin of 5 SNS's is China (27.8\%), country of origin of 1 SNS's is Israel, 1 SNS Korea, and 1 SNS is Russia (approx.. $5.5 \%$ ) (as shown in Table 2). 


\begin{tabular}{|c|c|c|}
\hline Social Media & Owner & Country of Origin \\
\hline Facebook & Mark Zuckerberg & USA \\
\hline $\begin{array}{l}\text { QQ (Tencent QQ) } \\
\end{array}$ & Tencent Holdings Limited & China \\
\hline WhatsApp & Jan Koum (CEO) & USA \\
\hline Facebook & Mark Zuckerberg & USA \\
\hline \multicolumn{3}{|l|}{ Messenger } \\
\hline QZone & Tencent Holdings Limited & China \\
\hline WeChat & Tencent Holdings Limited & China \\
\hline Twitter & Jack Dorsey & USA \\
\hline Skype & Microsoft Corporation & USA \\
\hline Google+ & Alphanet Inc. & USA \\
\hline Instagram & Facebook (so Mark Zuckerberg) & USA \\
\hline Baidu Tieba & Baidu & China \\
\hline \multirow[t]{2}{*}{ Viber } & $\begin{array}{lll}\text { Talmon } & \text { Marco } & \text { (Marco }\end{array}$ & Israel \\
\hline & Magazinnik) & \\
\hline TumbIr & Yahoo! & USA \\
\hline Line & Naver (South Korea's Naver Corp.) & Korea \\
\hline Snap chat & Bobby Murphy & USA \\
\hline Sina Weibo & Sina Corp. & China \\
\hline VKontakte & Pavel Durov & Russia \\
\hline Likedin & Reid Hoffman and his Team & USA. \\
\hline
\end{tabular}

Table 2. The Leading Social Networks worldwide, Owners, Country of Origin

I do believe that the main and one of the most significant peculiarity of new media that makes it new, is that they comprise more than one type of communication genres within itself; interpersonal communication, group communication, and mass communication. Therefore, it requires redefining the traditional categorization of communication genres. The second important peculiarity of new media is to redeem its users from spatial-temporal restrictions of 
real world as well as giving control of disseminating information, to some extent, to its users within the context of time with a variety of options. It eased social communication and it enabled reaching information as well as people with a single click, at any time, not only from limited channels but from any source.

However, as with every innovation, new media has brought some risks with itself. The main problem at this point is to determine the representation of the dominant new media that can be classified as new mainstream media in traditional (old) mainstream media such as Hollywood cinema. Because of this, for the purpose of the study, a drama film and biography "The Social Network" movie is examined, which was released in the United States by Columbia Pictures in 2010.

As is known, there are several approaches that attempts to interpret what the movie is about. The present study focuses only on Marxist critic, which is defined by Jacobs (n. d.) as critic that "attempt to associate characters and events in a film as representative of class struggle, labor vs. management, poor vs. rich, oppressive governments, and other Marxist sociopolitical concerns". As mentioned above, the theory that is taken for granted during the present study is the Screen Theory, which is a concern in the Marxist Theory. According to the theoreticians of this approach, MacCabe, Heath, and Mulvey, it is the spectacle that creates the spectator and not the other way round. The fact that the subject is created and subjected at the same time by the narrative on screen is masked by the apparent realism of the communicated content.

Additional theory that will be used is the Apparatus Theory, which originated from the Marxist film theory too, as well as semiotics and psychoanalysis. It was a dominant theory within cinema studies during the 1970s. According to this theory "cinema is by nature ideological because its mechanics of representation are ideological" (Esomba, 2013, p.5). Cinema's representation mechanics comprises the camera and editing. As mentioned by Esomba (2013), "the central position of the spectator within the perspective of the composition is also ideological". This theory also insists that cinema legitimates and naturalizes the dominant ideology of the culture within the audiences. Ideology is assumed to be part of its nature, although not imposed on cinema. Because of this, for the purpose of the present study, specifically, narration of the film and representation of "Mark Zuckerberg" as 
well as 'The Facebook' as personalized social network site within context of "heroising" is analyzed.

\section{The Social Network}

\section{Plot}

"The Social Network", whichhas no difficulty in attaching spectators to the movie via the used humble effects, fiction, and cinematography, is about the biography of "Mark Zuckerberg" and thus "Facebook" which can be assumed to be both as an "extension" and "indispensable" of offline lives. The motion picture, of which some scenes became cover page of some of the textbooks (e.g. The film Experience, Corrigan, T., \& White, P. 2012), is not only about the innovation of Facebook but also informs its spectators about how it is naturalized and normalized in daily lives as an indispensable part of our lives. The main idea and feelings that are cultivated by the movie are done through camera angles and soundtracks as well as other visual effects

The film is the story of Mark Zuckerberg, who is the CEO and founder of a social network site (Facebook), which became a social phenomenon with billions of users, and his relationships with some of his friends during the development process of Facebook. Realities lie behind Facebook, which is one of the dominant SNS, such as the story of its formation and the advantages/disadvantages offered by it are all subjected through the story of Mark Zuckerberg.The movie is about a young man who has low self-confidence, low self-esteem, and so was struggling to come in from the cold; a young man who thought himself 'worthless' and struggled for 'existence'; a young man who became one of 'the world's youngest billionaires' by the end. The movie begins with "Ball and Biscuit", which is the song of The White Stripes, and ends with "Baby, You're a Rich Man" of the Beatles to indicate the ground that was covered.

\section{Aesthetic}

The movie starts at one of the humble bars, with the dialog between a boy and a girl. The scene was presented from eye view to attach the spectators to the movie as a part of the atmospheric environment. In this scene, Marc is naturalized and normalized similar to an ordinary person. On the other hand, via the flow of the conversation and the complex structure of Mark's discourses, spectators can easily differentiate him from them in terms of 
intelligence and uncommonness. As Zukerberg's girlfriend ends their relationship, the camera angle changes and a high angle shot is used when showing him to the audiences to refer to his 'lovelornness' and to highlight that he has become a 'persona non grata'.

While running from the bar where his girlfriend ended their relationship to his room at the dormitory, which was the indicator of his efforts in his life, he was followed by the camera. This scene, which was one of the longest scenes of the movie, was the signifier of the point that he had arrived. Camera angles, in furtherance, were also used. At some points, a high angle shot was used to indicate his failures and inferiority, at some points a low angle shot was used (e.g., entrance to dormitory) to highlight his success and superiority.

Likewise, as he began doing something at the computer, a low angle shot was used to indicate the ability of Mark at information technologies and his superiority in this field. In addition to this, at the first scene where he entered his room, Mark who opened the mini bar to get a beer to drink, picked the bottle of beer was kept with the label facing inward. The purpose of this aesthetic detail was to cultivate 'distinctness' of Mark Zuckerberg from the beginning of the movie. Verbal narration of the movie was done directly by Mark Zuckerberg, parallel to showing the things he had done to attach spectators to the flow of the story. Second reason for this is to create a feeling of 'listening his story from him' and to sympathize with him. However, as mentioned above, complicated discourses of Zuckerberg and the jargon that he used, on the other hand, differentiated him from the spectators. He was suggesting and believing that by being a member of an elite group or club, it would help everyone (including himself) to be 'accepted'. His belief was supported via transitions from room to room on the first party scene. 


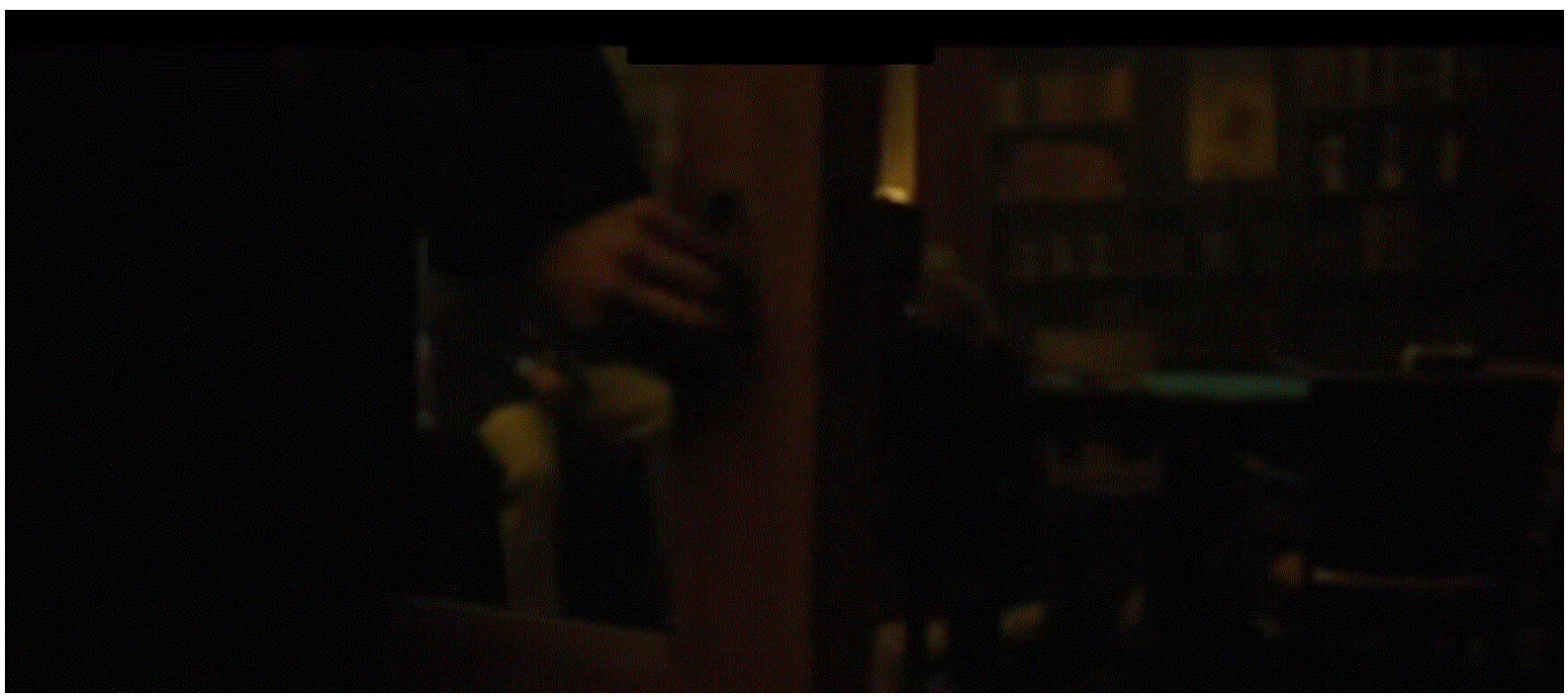

Image 1. Partying as welcome to elite group

In addition to this, as he entered the 'porcelain club' dormitory, which only members of elite groups can enter, a low angle shot was used to refer to his 'climb'. During legal meetings, the camera mostly was focused on Mark and the rest were mostly blurred to manipulate the perception of the spectators about the significance of the people there. In most of the scenes, everybody and everything apart from Mark was blurred to 'heroize' and to 'trivialize' the rest. This idea was also supported by the camera angles to indicate his normality as well as his 'successes'.

The scene at the restaurant to which Mark and his friends went to meet with Sean, was a lowangle shot, background music was to drown conversations and the only sound was from the glasses. These were to highlight that it was the turning point of their lives. Competitions and contentions in the movie were also highlighted by the visual effects. One of the most distinct scenes was the one that showed the Winklevoss brothers in rowing race in slow motion and concordantly the activation of Facebook all around the world. From this scene, inferiority of brothers compared to Mark Zuckerberg was projected to the spectators. He lost his friend, Eduardo, during the legal process regarding the innovation and rights of Facebook. This was shown by the position of Eduardo at the meeting (he was the only one who was sitting facing away) and was also supported by the visual effects (Mark was blurred to be shown as 'faulty' and 'inferior'). At the end of the movie, victory of Mark and thus Facebook, that is, attaining his objective about being 'popular', was highlighted by playing "Baby, You're a Rich Man" of the Beatles,. 


\section{Character}

The movie was emphasizing the significance of Facebook in our daily lives, and the persona of Mark Zuckerberg was highlighted. Overall, Mark was portrayed as big head, wise, and sarcastic guy. Argument about his genius was emphasized via the narration and cinematography of the movie. When mentioning the fact that the number of genius people in China is much more than in the US, he was claiming his 'uniqueness' and his 'speciality'. Via his manners and speeches, he always attempted to "inferiorize" and 'humiliate' other people either woman or man. As an antisocial personality, Mark was portrayed as a guy who has low self-esteem, a guy who did not realize himself, and a one who is poor in social relations. He was represented as a young man who has no self-esteem, which is one of the characteristics of a self-actualized person.

Mark, whose girlfriend had deserted him, felt raw about it and had humiliated her in his 'blog'. He also created 'Face-match' program to compare female students of the universities to insult them through their physical appearances. He wanted to make them feel what he was feeling about being 'undesirable' because of physical appearance. This scene indicated the fact that he was feeling anger toward the opposite sex because of his low self-confidence regarding his physical appearance. Mark's obsession about being elite or popular (but not being rich) to be admitted was repeated throughout the movie. According to him, being elite was all about being popular and the structure of the 'super-class' was only about being popular. He was portrayed as someone who was 'othering' people through his 'intelligence' in most of the scenes (such as othering his girlfriend through the university she was studying). His lack of self-confidence about his physical appereance was indicated at the very beginning of the movie, the opening scene, where he confessed to his girlfriend that he had no chance of being popular because of his physical appearance. Despite his intelligence and high IQ, he was portrayed as a guy who has low EQ (emotional quotient) because of being poor at social relations. Regarding this, he was represented as someone who has potential to trust anybody. This detail was given to the spectators as the mitigating causes of his negative features. It was also supported via the conversation between him and solicitress who told him that he was not a 'cur' but he only tried to be one.

His marginality within the context of his appearance was highlighted through the cinematography of the movie not to indicate his modestness but to point to his nonchalance 
and facetiousness. Likewise, there is a nuance between being modest and being nonchalant. At the first legal meeting that he was involved in, everyone apart from him were wearing suits. He was the only one who presented himself with flip flops, t-shirt, and a jean. In addition to this, in the one of the following scenes, he was shown going to job interview to tell them to 'go to hell' with a robe-de-chambre and sleepwear.

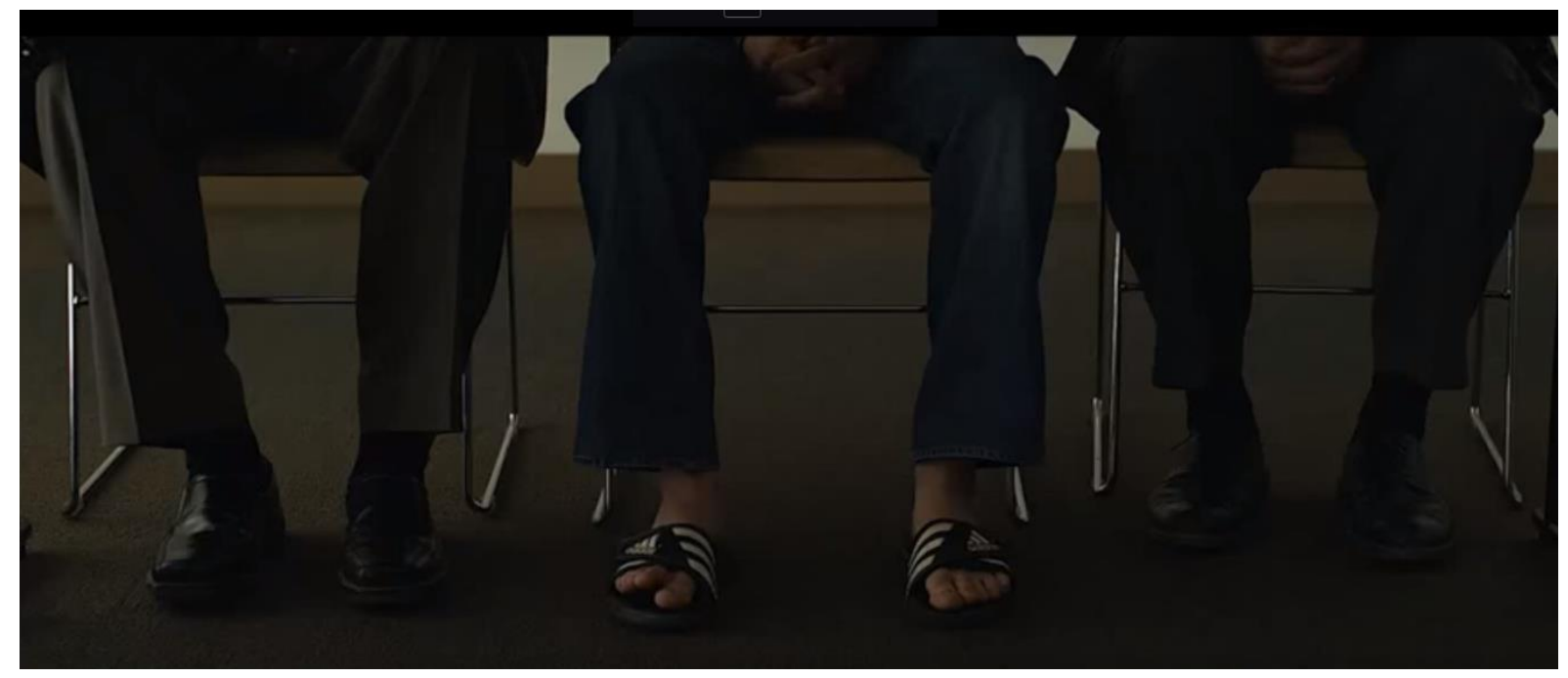

Image 2. Mark Zuckerberg at Hovards's Ad Board with flip flops

Apart from his contrarian dressing style, his apathy, and sarcastic attitudes, drawing pictures or scratching during the legal meetings as well as giving sarcastic answers to the questions that are posed him, supports his pertness.

His understanding about popularity was not related with the money or attention of opposite sex. For this reason, he never concerned himself with womanizing or earning money. On the contrary, being 'an endless project' or being 'fashion' in other's life such as 'Facebook' was the only important thing for him in terms of being popular and not losing it. His ambitious persona, so ambitious that he faced losing his best friend, was highlighted during the movie. However, his 'naiveté' or his emotional intelligence level was presented to spectators as extenuating circumstances.In the movie, his bullheaded, unsubmissive persona was intertwined with a young man who never apologizes and is evasive. This was shown as how Mark was being different and successful.

\section{Implications}

This motion picture, which only shows a particular part of Mark Zuckerberg's life (innovation and development of Facebook SNS), is one of the biopics that legitimates the power of 
'representations' within the context of constructing and reconstructing realities.Cinematography, effects, and lightings were intertwined, were harmonious and professionally manipulative in the film. Forasmuch as before analyzing the movie, as the only social network site that was filmed as a biopic, I was almost sure that the 'place' of Facebook in our everyday lives would be naturalized and legitimated via this cinematographic apparatus.

To summarize, Mark, who has various negative features, does not leave a negative impression with the spectators because of the success of the movie at its narration and fiction. Despite all negativities, such a motion picture, which had said that Mark did a good job and he squeezed out, indicates the active power of cinema industry on social consciousness and construction of social reality. How 'old' media deals with 'new' media and how they legitimate already constructed power relations, the way they naturalize and cultivate the concept of 'new' although not being very different from the 'old' media is, to some extent, indicated via this motion picture as a means of cinematographic apparatus. 


\section{References}

Barker, C. (2004). The Sage dictionary of cultural studies. Sage.

Bullying (2015). In Oxford Dictionaries; Language Matters (online). Oxford University Press Esomba, P. S. N. (2013). Moving Cameras and Living Movies.

Hall, S. (2005). Encoding/decoding. In Centre for Contemporary Cultural Studies (Eds.): Culture, Media, Language: Working Papers in Cultural Studies, 1972-79, London Hutchinson, 117-27.

Jacobs, C. P. (n.d). Film Theory and Approaches to Criticism,or, What did that movie mean?. Also available at: http://www.und.edu/instruct/cjacobs/FilmTheory\&Analysis.htm Krämer, P. (2002). The Best Disney Film Never Made: Children's Films and the Family Audience in American Cinema since the 1960s', in Genre and Contemporary Hollywood, ed. Steve Neale. London: British Film Institute, pp. 185-200.

Laughey, D. (2010). Media Studies: Theories and Approaches. Harpenden: Oldcastle Books. Morley, D. (2005). Texts, readers, subjects. In Centre for Contemporary Cultural Studies (Eds.): Culture, Media, Language: Working Papers in Cultural Studies, 197279, London Hutchinson, 154-65.

Nichols, B. (1976). Movies and methods: An anthology. Berkeley: University of California Press.

Williams, R. (1985). Keywords: A vocabulary of culture and society. Oxford University Press.

Rushton, R., \& Bettinson, G. (2010). Apparatus theory: jean-Louis Baudry and Christian Metz. In What is film theory?: An introduction to contemporary debates. (e-book, pp. 34-52) Maidenhead, Berkshire: Open University Press. Retrieved from www.bookzz.org

Sareah, F. (Jul 26, 2015). Interesting Statistics for thr Top 10 Social Media Sites. Retrieved from: http://smallbiztrends.com/2015/07/social-media-sites-statistics.html

Sire, J. W. (2000). Habits of the mind: intellectual life as a Christian calling. InterVarsity Press. 